\title{
Prostate Biopsy: Which Technique for Which Results at Lomé University Hospital in 2017?
}

\author{
Tchilabalo Matchonna Kpatcha ${ }^{1}$, Tchin Darré2 , Essodina Padja1, \\ Adolphe Essomindedou Leloua1, Gnimdou Botcho³ ${ }^{3}$ Edoé Viyomé Sewa1, Kodjo Tengue1, \\ Komi Hola Sikpa ${ }^{3}$, Ekoué David Dosseh ${ }^{4}$
}

\author{
${ }^{1}$ Department of Urology, University Teaching Hospital of Lomé, Lomé, Togo \\ ${ }^{2}$ Department of Pathology, University Teaching Hospital of Lomé, Lomé, Togo \\ ${ }^{3}$ Department of Surgery, University Teaching Hospital of Kara, Kara, Togo \\ ${ }^{4}$ Department of Surgery, University Teaching Hospital of Lomé, Lomé, Togo \\ Email: ^fakpatcha@yahoo.fr
}

How to cite this paper: Kpatcha, T.M., Darré, T., Padja, E., Leloua, A.E., Botcho, G., Sewa, E.V., Tengue, K., Sikpa, K.H. and Dosseh, E.D. (2018) Prostate Biopsy: Which Technique for Which Results at Lomé University Hospital in 2017? Open Journal of Urology, 8, 125-133. https://doi.org/10.4236/oju.2018.84014

Received: December 19, 2017

Accepted: April 25, 2018

Published: April 28, 2018

Copyright (c) 2018 by authors and Scientific Research Publishing Inc. This work is licensed under the Creative Commons Attribution International License (CC BY 4.0).

http://creativecommons.org/licenses/by/4.0/

\begin{abstract}
Background: Diagnosis of prostate cancer is certified by histology true prostate biopsies. The aim of our study was to evaluate our prostate biopsy method. Material and Methods: It was a prospective study including patients underwent prostate biopsy. Inclusion criteria were prostate specific antigen (PSA) level up to $4 \mathrm{ng} / \mathrm{ml}$ and/or abnormal prostate at digital rectal examination. Patients who had risk factors of bleeding have been excluded of the study. The preparation before biopsy included antibioprophylaxy (Ciprofloxacine-Tinidazole) and rectal hypertonic cleaning $\left(\right.$ Normacol $\left.^{\star}\right)$. Twelve cores have been taken in each prostate by transrectal digital-guided way, using Biopty Gun 18 Gauge. Local anesthesia has been done previously by intrarectal application of $20 \mathrm{ml}$ of gel of Lidocaïne. Two other cores were taken into each abnormal area at rectal examination. The follow-up have been done during twelve weeks. Results: Eighty patients of 65 years of age were included. Nine patients had familial history of prostate cancer. PSA levels ranged from 5 to $6400 \mathrm{ng} / \mathrm{ml}$ with a median of $26.77 \mathrm{ng} / \mathrm{ml} \pm 11.2$. Complications occurred in $11.25 \%$ of patients, principally infectious complications which caused death of one patient by septicemia. The rate of cancer detection was $20 \%$. Prostate abnormality at digital rectal examination and the presence of familial history of prostate cancer were not predictive factors of the presence of cancer on cores. Conclusion: Our prostate biopsy method is limited by the lack of ultrasonographic guidance and is at important risk of infectious complications.
\end{abstract}

\section{Keywords}

Biopsy, Prostate Cancer, Digital Guidance, Infectious Complications 


\section{Introduction}

Prostate cancer is now a real public health problem because of its ever-increasing prevalence [1]. The wide use of the prostate specific antigen (PSA) assay for screening has caused the incidence to explode in a general way. But the diagnosis of certainty is histological and is based on the analysis of prostate tissue samples generally obtained by biopsy. This prostate biopsy can be done mainly by two routes, the transrectal and the transperineal route. But whatever the route used, this procedure is burdened with fairly high morbidity and mortality that is not zero [2]. According to the recommendations for the good practice of prostate biopsies, 12 ultrasound-guided transrectal samples make it possible to optimize the detection of carcinomatous foci [3]. In our practice screening for prostate cancer is routine in any patient receiving urology and at least 50 years of age, and the biopsy specimen of the prostate is proposed in case of clinical and/or biological suspicion of neoplasia. It seemed important to know the impact of the prostate biopsy as it is performed in our practice on the detection of prostate cancer and the risks of this procedure. The aim of our study was to report the technique and results of a series of prostate biopsies and to analyze its interest in the diagnosis of prostate cancer.

\section{Material and Methods}

We conducted a 24-month prospective study (from January 2016 to December 2017) that included patients who had a prostate biopsy for the diagnosis of prostate cancer. The inclusion criteria were a total PSA level greater than 4 $\mathrm{ng} / \mathrm{ml}$ [4] and/or a digital rectal abnormality. A biological assessment including blood crase and cytobacteriological examination of urine (ECBU) was done for each patient. Patients who were at risk of bleeding (abnormal haemostasis, anticoagulation) were excluded from the study, and those with bacteriuria greater than $105 / \mathrm{ml}$ were treated with appropriate antibiotics before biopsy. Each patient received antibiotic prophylaxis beginning forty-eight hours before the biopsy, including $500 \mathrm{mg}$ of ciprofloxacin and $400 \mathrm{mg}$ of tinidazole every $12 \mathrm{~h}$; the antibiotics were pursued after the biopsy for $48 \mathrm{~h}$. A rectal preparation was administered to all patients and consisted of a Normacol enema* four hours before the procedure. Prostate tissue was sampled by transrectal way under local anesthesia by intrarectal administration of $20 \mathrm{ml}$ of lidocaine gel; the operator was the same for all patients. The puncture material was a Biopty Gun $18 \mathrm{G}$ disposable forceps (Figure 1).

Twelve samples were systematically taken on each prostate, four at the base (including two on each lobe), four at the middle and four at the apex. Two additional samples were taken from any nodule or induration identified by digital rectal examination. Patient follow-up included an examination on day 1 (D1), D2, D7, D14 and D28 post biopsy; the monitoring elements included temperature, bleeding (hematuria, rectorrhagia, hemospermia), urine retention or any other clinical manifestation following the biopsy. For patients who have had one or more complications, hospitalization and adequate treatment have been 


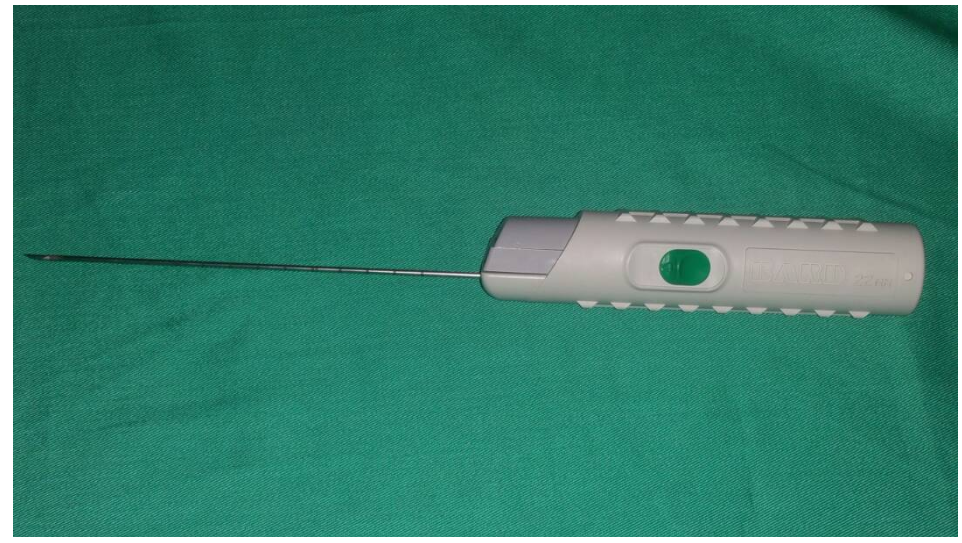

Figure 1. Biopty Gun biopsy forceps for single use.

instituted. The total PSA assay was repeated 60 days after the biopsy if the histological examination showed no carcinomatous lesions. A second biopsy was offered to the patient if this control rate was greater than $4 \mathrm{ng} / \mathrm{ml}$. The parameters studied were the age of the patients, the tolerance of the procedure (evaluated by the EVA visual analogue scale), the family history of prostate cancer, the initial total PSA level, the appearance of the prostate in the digital rectal examination, the result of the histological examination (histological nature of the tissue and Gleason score in case of malignancy), the post-biopsy complications, the post-biopsy PSA and whether or not a second prostate biopsy is performed and its result, as well as the detection rate after the first biopsy series and after the second series.

\subsection{Statistical Analysis}

The data was analyzed by Epi info version 3.5.4. The threshold of significance was represented by a $p$-value $<0.05$. Consent was obtained from all patients who participated in this study.

\subsection{Ethical Consideration}

This study received approval from the Head of the Urology department to be conducted. Since it was counting records, patient consent was not required. However during the counting and data collection patient names were not collected in order to preserve confidentiality.

\section{Results}

Out of a total of ninety-two patients, eighty met the criteria and were included in the study. Their median age was 65 years \pm 8.5 ( 52 years old and 85 years old). Nine patients had a family history of prostate cancer including seven first degree and two second degree. The initial total PSA level ranged from $5 \mathrm{ng} / \mathrm{ml}$ to 6400 $\mathrm{ng} / \mathrm{ml}$ with a median of $26.77 \mathrm{ng} / \mathrm{ml} \pm 11.2$. The detection rate of prostate cancer was $20 \%$ on the first series of samples and $33.3 \%$ on the second series which concerned only three patients. The abnormality of the prostate gland at the digi- 
tal rectal examination was not a predictive factor for the presence of carcinoma on the biopsy samples and the presence of a family history of prostate cancer in the patient was not correlated with the histological results (Table 1). The patients' tolerance of the procedure was low; the pain was estimated at 7/10 on the visual analogue scale (VAS).

Complications occurred after prostate biopsy in 9 patients corresponding to $11.25 \%$. These were mainly infectious complications (Table 2). We noted a death in a diabetic patient who had not observed antibiotic prophylaxis; the isolated organism was $E$. coli sensitive to quinolones. The death occurred two weeks after the biopsy despite appropriate antibiotic therapy.

Histologically, the adenocarcinoma had a variable level of differentiation, the distribution according to the Gleason score and the corresponding values of the PSA level are presented in Table 3. Mean PSA levels at one month and three months after biopsy were $80.78 \mathrm{ng} / \mathrm{ml}$ and $68.46 \mathrm{ng} / \mathrm{ml}$, respectively.

\section{Discussion}

We analyzed the results of the digitally guided transrectal prostate biopsy performed in eighty patients through a prospective study. Complications occurred in the immediate aftermath in $11.25 \%$ of patients, mainly infectious complications and one death. The detection rate of prostate cancer in our series was $20 \%$. The digital rectal examination abnormality was not significantly correlated with the risk of cancer detection on biopsy samples. The family history of prostate cancer had no correlation with the detection rate.

Table 1. Correlation between prostate cancer rates, Digital Rectal Examination (DRE) and Family History.

\begin{tabular}{cccc}
\hline & $\begin{array}{c}\text { Positive biopsy } \\
\text { rate (\%) }\end{array}$ & $\begin{array}{c}\text { Negative biopsy } \\
\text { rate (\%) }\end{array}$ & $p$ \\
\hline Abnormal prostate at DRE & $44.11(15 / 34)$ & $55.88(19 / 34)$ & 0.06 \\
Normal prostate at DRE & $2.17(1 / 46)$ & $97.82(45 / 46)$ & 0.01 \\
$\begin{array}{c}\text { Patients with a family history of } \\
\text { prostate cancer }(\mathbf{n}=9)\end{array}$ & $11.11(1 / 9)$ & $88.88(8 / 9)$ & 0.09 \\
$\begin{array}{c}\text { Patients with no family history of } \\
\text { prostate cancer }(\mathbf{n}=71)\end{array}$ & $21.12(15 / 71)$ & $78.87(56 / 71)$ & 0.1 \\
\hline
\end{tabular}

Table 2. The different complications in the follow-up of the prostate biopsy.

\begin{tabular}{cccc}
\hline & Type & Number & Percentage \\
\hline $\begin{array}{c}\text { Infectious } \\
\text { complications }\end{array}$ & Acute prostatitis & 6 & 7.50 \\
$\begin{array}{c}\text { Orchi-epididymitis } \\
\text { Hemorrhagic } \\
\text { complications } \\
\text { Total }\end{array}$ & Hepsis (death) & 1 & 1.25 \\
\hline
\end{tabular}


Table 3. Correlation between PSA and Gleason score.

\begin{tabular}{|c|c|c|c|c|}
\hline & Gleason score & $\begin{array}{c}\text { PSA } \\
\text { average }\end{array}$ & $\begin{array}{c}\text { PSA extremes } \\
\text { (minimum - maximum) }\end{array}$ & $\begin{array}{l}\text { Number } \\
(\mathrm{N}=16)\end{array}$ \\
\hline $\begin{array}{l}\text { Undifferenciated } \\
\text { tumor }\end{array}$ & $8(5+3)$ & 6400 & - & 1 \\
\hline \multirow{4}{*}{$\begin{array}{l}\text { Medium differenciated } \\
\text { tumor }\end{array}$} & $7(4+3)$ & 522.71 & $42-2233$ & 5 \\
\hline & $7(3+4)$ & 98.24 & - & 1 \\
\hline & $6(4+2)$ & 626.5 & $53-100$ & 2 \\
\hline & $6(3+3)$ & 732.21 & $525-939.43$ & 2 \\
\hline \multirow{3}{*}{$\begin{array}{l}\text { Tumor well } \\
\text { differenciated }\end{array}$} & $5(3+2)$ & 30 & - & 1 \\
\hline & $5(2+3)$ & 140.95 & - & 1 \\
\hline & $4(2+2)$ & 807.11 & $34.3-2142$ & 3 \\
\hline
\end{tabular}

\subsection{Procedure Limitations}

The technique of digitally guided sampling in prostate biopsy has limitations related to the lack of precision in the choice of areas to be taken. Despite a grid of the gland, the cancer detection rate in our series was surely below what it could be if we had had imaging guidance. Indeed, the standard prostate biopsy technique currently accepted is transrectal guided echo sampling [3], even though the latter would ignore about $20 \%$ of prostate cancer that would have required treatment [4]. To overcome these shortcomings, new guidance techniques are currently being used, including Magnetic Resonance Imaging (MRI), which significantly increases the clinically significant cancer detection rate as reported by Futterer [5]. In our series the refusal of the majority of patients to undergo a second biopsy, related to the discomfort of the procedure including pain, reduced the number of cancer cases diagnosed in the second series. This second series of biopsies would surely have significantly increased the detection rate, given the permanent rise in PSA levels during follow-up.

\subsection{Infectious Complications}

Infectious complications were particularly common in our series despite antibiotic prophylaxis. The use of antibiotic therapy for surgery is questionable, but in the case of prostate biopsy it is a necessary precaution demonstrated by several studies [6] [7] [8] [9]. The discussion nevertheless lies in the modality of this antibiotic prophylaxis. In a series comparing the results of two groups of patients, one of which had taken a single dose and the second of multiple doses of a Ciprofloxacin-Metronidazole combination, authors reported a lower rate of bacteriuria in the multiple-dose group [10], but the rates of fever and sepsis were the same in both groups. A single dose would therefore be sufficient for the prophylaxis of prostate biopsy. The choice of molecules used in our series was based on the sensitivity of uropathogenic germs, even though recent publications reported increasing resistance of Escherichia coli to quinolones and particularly to ciprofloxacin [11]. Antibiotic prophylaxis of the prostate biopsy is important but 
even more so in the patient with one or more risk factors, the risk of spread of a possible infection being indeed increased in case of weakened ground. In our study the diabetic patient died due to septicemia at the starting point of the prostate, this sepsis could certainly have been avoided if the doses of antibiotics had been taken in advance, but diabetes is currently considered to be one of the risk factors for quinolone resistance [12]. Antibiotic prophylaxis adapted to the result of rectal swab sampling would reduce the risk of infection [13].

\subsection{Different Routes and Tolerability}

Compared with the transperineal route, the transrectal route appears to provide less pain, but with a higher risk of rectorrhagia [14] [15]. In the series of Hara [16], no difference was noted in terms of pain manifestations between patients who had had a transrectal biopsy compared to those who had had a transperineal biopsy, but the anesthetic method used was spinal anesthesia. Perineal infiltration of xylocaine combined with periprostatic infiltration would not be sufficient in the transperineal approach, and authors reported that for this pathway the best options would be pudendal block, caudal block or spinal anesthesia [16] [17]. The use of intra rectal ice has been tested by some teams with benefits on the perception of pain [18] [19]. The maneuver was perceived as very painful in our series. This is explained by our procedure of anesthesia which seems less effective than the periprostatic block, as authors had reported [20] [21] [22]. This low tolerance has resulted in the majority of our patients refusing to undergo a second series of samples. It thus appears clear that ultrasound guidance, which allows at the same time achieving periprostatic anesthesia and identifying areas to collect allow us to ensure the comfort of our patients while keeping the ambulatory nature of the procedure.

\subsection{Cancer Detection Rate}

Our detection rate (20\%) is lower than the rates reported in the literature [23] [24] [25] [26]. This difference is explained by our "blind" method which limits the detection of small non-palpable fireplaces DRE. Several devices are currently used to improve the targeting of suspicious prostate areas. Apart from ultrasound guidance, which is now the routine biopsy sampling technique [3], magnetic resonance imaging (MRI) has been described as to significantly increase the detection and especially high-risk cancers [27]. In our case, this exploration is not very accessible because of its high cost; it is realized only for patients with a strong economic power and after negative biopsy series with PSA levels always high.

The abnormality of the prostate on digital rectal examination was not a predictor of the presence of prostate cancer on the samples in our series. DRE had a high sensitivity and low specificity in our series, indeed among patients in whom the prostate was clinically normal up to $97.82 \%$ had a negative biopsy while only $44.11 \%$ of those whose prostate had malignancy had a positive biopsy. Rozet et 
al. reported that a suspicious digital rectal scan was associated with a higher risk of undifferentiated tumor regardless of the value of PSA [28]. The low specificity of rectal examination in our patients can be explained by a high rate of chronic prostatitis. In fact lesions of chronic prostatitis were detected on about two-thirds of the samples. The presence in the patient of a family history of prostate cancer was not significantly correlated with the positivity of prostate biopsy, but this result is probably due to the weakness of our series.

\section{Conclusion}

Our study has highlighted the limitations and the high infectious risk of our prostate biopsy technique. Ultrasound guidance could increase the detection rate; the patient's preparation should be strengthened to significantly reduce the infections inherent in this procedure.

\section{References}

[1] Darré, T., Folligan, K., Kpatcha, T.M., Kanassoua, K., Sewa, E., Daré, S., et al. (2017) Evolution of the Histo-Epidemiological Profile of Urological Cancers in Togo. Asian Pacific Journal of Cancer Prevention, 18, 491-494.

[2] Lechevallier, E. (1996) Prostate Biopsy. Progrès en Urologie, 6, 507-518.

[3] Ouzzane, A., Coloby, P., Mignard, J.P., Allegre, J.P., Soulie, M., Rebillard, X., et al. (2011) Recommendations for the Good Practice of Prostate Biopsy. Progrès en Urologie, 21, 18-28.

[4] Busato, W.F.S., Almeida, G.L., Geraldo, J., Busato, F.S. (2015) Does PSA Reduction after Antibiotic Therapy Permits Postpone Prostate Biopsy in Asymptomatic Men with PSA Levels between 4 and $10 \mathrm{ng} / \mathrm{ml}$ ? International Brazilian Journal of Urology, 41, 329-336. https://doi.org/10.1590/S1677-5538.IBJU.2015.02.21

[5] Futterer, J.J., Briganti, A., De Visschere, P., Emberton, M., Giannarini, G., Kirkham, A., et al. (2015) Can Clinically Significant Prostate Cancer Be Detected with Parametric Magnetic Resonance Imaging? A Systematic Review of the Literature. European Urology, 68, 1045-1053. https://doi.org/10.1016/j.eururo.2015.01.013

[6] Bootsma, A.M., Laguna Pes, M.P., Geerling, S.E. and Goosens, A. (2008) Antibiotic Prophylaxis in Urologic Procedures: A Systematic Review. European Urology, 54, 1270-1286. https://doi.org/10.1016/j.eururo.2008.03.033

[7] Sabbagh, R., McCormack, M., Peloquin, F., Faucher, R., Perreault, J.P., Perrotte, P., et al. (2004) A Prospective Randomized Trial of 1-Day versus 3-Day Antimicrobial Prophylaxis for Transrectal Ultrasound Guided Prostate Biopsy. Canadian Journal of Urology, 11, 2216-2219.

[8] Briffaux, R., Coloby, P., Bruyere, F., Ouaki, F., Pires, C., Doré, B. and Irani, J. (2009) One Preoperative Dose Randomized against 3-Day Antibiotic Prophylaxis for Transrectal Ultrasonography Guided Prostate Biopsy. BJU International, 103, 1069-1073. https://doi.org/10.1111/j.1464-410X.2008.08128.x

[9] Webb, N.R. and Woo, H.H. (2002) Antibiotic Prophylaxis for Prostate Biopsy. BJU International, 89, 824-828. https://doi.org/10.1046/j.1464-410X.2002.02735.x

[10] Heidari Bateni, Z., Shahrokh, H., Salimi, H., Safari, H., Tabatabai, M. and Saedi, D. (2014) Single-Dose versus Multiple-Dose Ciprofloxacine plus Metronidazole Prophylaxis in Transrectal Ultrasound-Guided Biopsy of the Prostate: A Randomized Controlled Trial. Acta Medica Iranica, 52, 664-670. 
[11] Bruyere, F., Malavaud, S., Bertrand, P., Decock, A., Cariou, G., Doublet, J.D., et al. (2015) Prosbiotate: A Multicenter, Prospective Analysis of Infectious Complications after Prostate Biopsy. Journal of Urology, 193, 145-150. https://doi.org/10.1016/j.juro.2014.07.086

[12] Cohen, J.E., Landis, P., Trock, B.J., Patel, H.D., Ball, M.W., Auwaerter, P.G., et al. (2015) Fluoroquinolone Resistance in the Rectal Carriage of Men in Active Surveillance Cohort: Longitudinal Analysis. Journal of Urology, 193, 552-556. https://doi.org/10.1016/j.juro.2014.08.008

[13] Liss, M.A., Kim, W., Moskowitz, D. and Szabo, R.J. (2015) Comparative Effectiveness of Targeted vs Ampirical Antibiotic Prophylaxis to Prevent Sepsis from Transrectal Prostate Biopsy: A Retrospective Analysis. Journal of Urology, 194, 397-402. https://doi.org/10.1016/j.juro.2015.03.110

[14] Udeh, E.I., Amu, O.C., Nnabugwu, I.I. and Ozoemena, O.F.N. (2015) Transperineal versus Transrectal Prostate Biopsy: Our Findings in a Tertiary Health Institution. Nigerian Journal of Clinical Practice, 18, 110-114.

[15] Damiano, R., Oliva, A., Cantiello, F., Esposito, C., Perdona, S., De Sio, M., Bitonti, M., Sacco, R. and D'Armiento, M. (2003) Questionnaire Based Evaluation of Prostate Biopsy Complication Comparing Different Bioptic Schemes. Archivio Italiano Di Urologia, Andrologia, 75, 40-45.

[16] Hara, R., Jo, Y., Fujii, T., Kondo, N., Yokoyoma, T., Miyaji, Y. and Nagai, A. (2008) Optimal Approach for Prostate Cancer Detection as Initial Biopsy: Prospective Randomized Study Comparing Transperineal versus Transrectal Systematic 12-Core Biopsy. Urology, 71, 191-195. https://doi.org/10.1016/j.urology.2007.09.029

[17] Iremashvili, V.V., Chepurov, A.K., Kobaladze, K.M. and Gamidov, S.I. (2010) Periprostatic Local Anesthesia with Pudendal Block for Transperineal Ultrasound-Guided Prostate Biopsy: A Randomized Trial. Urology, 75, 1023-1027. https://doi.org/10.1016/j.urology.2009.09.083

[18] Çaliskan, B. and Mutlu, N. (2015) Intrarectal Ice Application Prior to Transrectal Prostate Biopsy: A Prospective Randomised Trial Accessing Pain and Collateral Effects. International Brazilian Journal of Urology, 41, 101-109. https://doi.org/10.1590/S1677-5538.IBJU.2015.01.14

[19] Ernst, E. and Fialka, V. (1994) Ice Freezes Pain? A Review of the Clinical Effectiveness of Analgesic Cold Therapy. Journal of Pain and Symptom Management, 9 , 56-59. https://doi.org/10.1016/0885-3924(94)90150-3

[20] Desgrandchamps, F., Meria, P., Irani, J., Desgrippes, A., Teillac, P. and Le Duc, A. (1999) The Rectal Administration of Lidocaine Gel and Tolerance of Transrectal Ultrasonography-Guided Biopsy of the Prostate: A Prospective Randomized Placebo-Controlled Study. BJU International, 83, 1007-1009. https://doi.org/10.1046/j.1464-410x.1999.00080.x

[21] Chang, S.S., Alberts, G., Wells, N., Jr. Smith, J.A. and Cookson, M.S. (2001) Intrarectal Lidocaine during Transrectal Prostate Biopsy: Results of a Prospective Double-Blind Randomized Trial. Journal of Urology, 166, 2178-2180. https://doi.org/10.1016/S0022-5347(05)65529-2

[22] Cevik, I., Ozveri, H., Dillioglugil, O. and Akdas, A. (2002) Lack of Effect of Intrarectal Lidocaine for Pain Control during Transrectal Prostate Biopsy: A Randomized Prospective Study. European Urology, 42, 217-220. https://doi.org/10.1016/S0302-2838(02)00275-0

[23] Brock, M., von Bodman, C., Sommerer, F., Loppenberg, B., Klein, T., Deix, T., et al. (2011) Comparison of Reel-Time Elastography with Grey-Scale Ultrasonography 
for Detection of Organ-Confined Prostate Cancer and Extra Capsular Extension: A Prospective Analysis Using Whole Mount Sections after Radical Prostatectomy. BJU International, 108, E217-E222. https://doi.org/10.1111/j.1464-410X.2011.10209.x

[24] Tavem, G., Morandi, G., Seveso, M., Giusti, G., Benetti, A., Colombo, P., et al. (2011) Colour Doppler and Micro-Bubble Contrast Agent Ultrasonography Do Not Improve Cancer Detection Rate in Transrectal Systematic Prostate Biopsy Sampling. BJU International, 108, 1723-1727.

https://doi.org/10.1111/j.1464-410X.2011.10199.x

[25] Mitterberger, M.J., Aigner, F., Horninger, W., Ulmer, H., Cavuto, S., Halpern, E.J. and Frauscher, F. (2010) Comparative Efficiency of Contrast-Enhanced Colour Doppler Ultrasound Targeted versus Systematic Biopsy for Prostate Cancer Detection. European Radiology, 20, 2791-2796.

https://doi.org/10.1007/s00330-010-1860-1

[26] Grabski, B., Baeurle, L., Loch, A., Wefer, B., Paul, U. and Loch, T. (2011) Computerized Transrectal Ultrasound of the Prostate in a Multicenter Setup (C-TRUS-MS): Detection of Cancer after Multiple Negative Systematic Random and in Primary Biopsies. World Journal of Urology, 29, 573-579. https://doi.org/10.1007/s00345-011-0713-0

[27] Siddiqui, M.M., Rais-Bahrami, S., Turkbey, B., George, A.K., Rothwax, J., Shakir, N., et al. (2015) Comparison of MR/Ultrasound Fusion-Guided Biopsy with Ultrasound-Guided Biopsy for the Diagnosis of Prostate Cancer. JAMA, 313, 390-397. https://doi.org/10.1001/jama.2014.17942

[28] Rozet, F., Hennequin, C., Beauval, J.B., Beuzeboc, P., Cormier, L., Fromont, G., et al. (2016) CCAFU 2016-2018 Oncourology Recommendations: Prostate Cancer. Progrès en Urologie, 27, S95-S143. 